\title{
Does Paternal Unemployment Affect Young Adult Offspring's Personality?
}

\author{
Viola Angelini \\ University of Groningen and Netspar \\ Marco Bertoni \\ University of Padova \\ Luca Corazzini \\ University of Venice and Bocconi University
}

Using longitudinal data from the German Socio-Economic Panel (SOEP), we analyze the impact of paternal unemployment on the "big five" personality traits of young adult offspring aged 17-25. Results from longitudinal value-added models for personality show that paternal unemployment makes offspring significantly more conscientious and - to a smaller extent-less neurotic. The uncovered effects are robust to the presence of selection on unobservables and correlation between the error term and the lagged outcome. We also discuss heterogeneous effects and the potential mechanisms behind our findings.

\section{Introduction}

Recent empirical evidence in both economics and psychology shows that personality traits have strong predictive power for a wide range of socioeconomic outcomes (Borghans et al. 2008a; Almlund et al. 2011; Brunello and Schlotter 2011; Bucciol, Cavasso, and Zarri 2015). Personality matters for job performances and wages (Barrick and Mount 1991; Salgado

\footnotetext{
We are grateful to the associate editor, two reviewers, Giorgio Brunello, Alessandro Bucciol, Deborah Cobb-Clark, Christopher Cotton, Arnaud Dellis, Monica Langella, Riccardo "Jack" Lucchetti, Jochen Mierau, Nattavudh Powdthavee, Enrico Rettore, Paolo Roberti, Lorenzo Rocco, Nicolas Salamanca, and Davide Ticchi for comments on earlier versions of this work and to the audiences at the 2015 Brucchi Luchino Workshop, the 2016 European Society for Population Economics Conference, and seminars at the University of Ancona, the University of Quebec at Montreal, Queen's University, and the University of Padova for useful discussions. Special thanks go to James MacKinnon, who provided invaluable suggestions for the design of our simulation exercises. We also thank Michaela Engelmann at the German Institute for Economic Research for providing us access to the data. The usual disclaimer applies. Marco Bertoni acknowledges funding from a Cassa di Risparmio di Padova e Rovigo foundation Starting Grant on "Education, Retirement and Household Behaviour."
}

[ Journal of Human Capital, 2018, vol. 12, no. 3]

( 2018 by The University of Chicago. All rights reserved. 1932-8575/2018/1203-0004 $\$ 10.00$ 
1997; Hogan and Holland 2003; Nyhus and Pons 2005), educational attainment (Goldberg et al. 1998; Duncan et al. 2007; Borghans, Meijers, and ter Weel 2008b; Poropat 2009), longevity (Roberts et al. 2007; Friedman, Kern, and Reynolds 2010; Savelyev 2014), health-related behaviors (Hampson etal. 2007), and criminal behaviors (John et al. 1994; O'Gorman and Baxter 2002). In their seminal work on the topic, Heckman, Stixrud, and Urzua (2006) showed that, by and large, the long-run effects of noncognitive skills - among which personality is also included —on labor market outcomes and social behavior are comparable to those of cognitive skills.

In spite of this evidence, surprisingly little is known about the effects of economic variables on noncognitive skills and personality in particular. According to the psychological literature, individual personality is still malleable until the "impressionable years" of early adulthood and then remains relatively stable throughout adulthood (Costa, McRae, and Arenberg 1980; Alwin 1994; Costa and McCrae 1994). ${ }^{1}$

Several papers have investigated how the economic external conditions experienced during the impressionable years shape young people's values, attitudes, beliefs, preferences, and well-being (among others, see Greenstein 1965; Hess and Torney 1967; Easton and Dennis 1969; Dennis 1973; Cutler 1974; Sears 1975, 1981, 1983; Krosnick and Alwin 1989; Giuliano and Spilimbergo 2014). As far as we know, however, there is limited empirical evidence on the contribution of both different socioeconomic factors and positive and negative life events to shaping personality not only in adulthood but also until the impressionable years. ${ }^{2}$

This paper contributes to the extant literature by estimating the effect of a relevant determinant of economic well-being of offspring, paternal unemployment, on personality traits, focusing on the crucial years of their development. ${ }^{3}$ Indeed, several studies suggest that by altering preexisting socioeconomic conditions of the family, paternal job loss has strong and persistent spillover effects on the life course of adolescents (Kalil and ZiolGuest 2008; Coelli 2011; Rege, Telle, and Votruba 2011; Stevens and Schaller 2011; Kind and Haisken-DeNew 2012; Powdthavee and Vernoit 2013; Pinger 2015). ${ }^{4}$ However, evidence about its effects on personality is still

${ }^{1}$ More specifically, psychologists (see Roberts and DelVecchio 2000) broadly distinguish between intraindividual stability, that is, stability of personality at the individual level over time in response to life events; mean-level stability, that is, population-level stability as time goes by; and rank-order stability, which refers to the relative placement of individuals within the population. The definition of stability that is relevant for our work is the intraindividual one.

${ }^{2}$ There is evidence suggesting that - at the individual level-personality traits are insensitive to changes in economic conditions (Cobb-Clark and Schurer 2012) during the working age. However, the stability of personality traits in adulthood has been questioned by Roberts, Walton, and Viechtbauer (2006), Roberts and Mroczek (2008), and Lucas and Donnellan (2011). In two recent papers, Boyce et al. (2015) and Anger, Camehl, and Frauke (2016) show that unemployment induces significant changes in personality.

3 We use the terms "offspring" and "children" interchangeably.

${ }^{4}$ From a macroeconomic perspective, previous research showed that recession periods affect several aspects of health (among others, see Ruhm 2015). 
lacking. ${ }^{5}$ A priori, it is hard to sign such an effect, and empirical analysis is needed to settle the matter. On the one hand, offspring may suffer from paternal job loss because of unemployment-induced parental depression (Powdthavee and Vignoles 2008) and deteriorated economic conditions of the family, which in turn are likely to generate a status of anxiety, frustration, and disillusionment (McLoyd 1989; Christoffersen 1994). On the other hand, unemployment may allow fathers to have more time to spend with their offspring, which may have positive effects on their personality development (see Powdthavee and Vernoit 2013 and references therein). Finally, as adverse life events have the potential to foster future resilience (see Seery, Holman, and Silver 2010; Seery 2011), fathers' negative experience may generate a coping mechanism on offspring, making them work hard and thoroughly to avoid falling into unemployment themselves.

Our analysis is based on data from the German Socio-economic Panel (SOEP), a unique household survey about the German population that collects longitudinal information on respondents' demographics, socioeconomic conditions, health, family composition, parental employment, and, last but not least, personality traits. Since SOEP longitudinally tracks all original household members even if they move out of the household, we can match offspring characteristics and the evolution of their personality traits over waves with the employment conditions of their parents. Hence, the comprehensiveness and the longitudinal nature of our data allow us to identify the link between the experience of paternal unemployment and offspring personality via a value-added model (see Todd and Wolpin 2003; Guarino, Reckase, and Wooldridge 2014). More specifically, we consider all offspring aged 17-25 whose fathers worked as employees in private firms at a given personality assessment, and we compare posttreatment personality traits of offspring whose fathers did and did not experience unemployment between two consecutive personality assessments, conditional on the offspring's baseline personality traits and a rich set of observable characteristics of the offspring and their parents-including parental personality traits and labor market histories. ${ }^{6}$ We measure personality in terms of the big five model (Goldberg 1993; Nyhus and Pons 2005; Barenbaum and Winter 2008; Krueger and Johnson 2008). According to this framework, personality can be summarized

\footnotetext{
${ }^{5}$ An exception is Pinger (2015), who reports that paternal unemployment has negative effects on academic confidence and locus of control. However, she considers younger children and does not look at the "big five" personality traits. Additionally, her identification strategy instruments individual unemployment status with local labor market variables, raising several concerns about the validity of the implied exclusion restrictions. For instance, in our context it would be hard to exclude the fact that local labor market variables may affect the unemployment probability of the fathers but not of the offspring. Another related study is Frauke (2016), who instead focuses on maternal unemployment episodes.

${ }^{6}$ Although one could imagine that the effects of paternal unemployment would be detected even at earlier ages, we can start only from age 17 because this is the earliest age at which individuals are interviewed in the SOEP.
} 
by five factors, namely, openness, conscientiousness, extraversion, agreeableness, and neuroticism.

We find a positive effect of paternal unemployment on the big five personality traits of their offspring during the impressionable years of early adulthood: experiencing paternal unemployment makes them significantly more conscientious and less neurotic - although this latter result is less robust to specification changes - while no significant effect is detected on the remaining three personality traits.

Our results are robust to a large battery of sensitivity tests, including $(a)$ different measurement methods for the big five personality traits; $(b)$ using robust regressions and simulations to verify that results from our relatively small sample are not driven by outliers; $(c)$ the use of instrumental variables and simulations to assess the bias of the effect of paternal unemployment caused by potential correlation between the error term and lagged personality — which would make ordinary least squares (OLS) estimates of value-added models inconsistent; $(d)$ tests for selection on unobservables (Altonji, Elder, and Taber 2005; Oster 2017); and (e) using semiparametric estimators.

To investigate potential mechanisms behind our uncovered effects, we also show that the effects on conscientiousness are positive and statistically significant only for older and employed offspring, who are likely to be more time constrained. This result implies that increased parent-child interactions are unlikely to be a mechanism behind our findings. Older and employed offspring are instead more exposed to the risk of unemployment and scared by its consequences. Therefore, finding stronger effects for this group suggests that the experience of a negative change in paternal employment may lead them to improve their sense of responsibility to avoid falling into unemployment themselves. Moreover, the (negative) effect of paternal job loss on neuroticism is group specific, as we document significant results only for females and children whose mothers are employed. As suggested by Heckman (2007) and Conti, Heckman, and Urzua (2010), this might in turn lead to a virtuous "self-productivity cycle," resulting in improved health and socioeconomic conditions throughout the life cycle.

\section{Data and Descriptive Analysis}

We use data from the German SOEP (2015), version 30. The SOEP is a representative annual panel survey of the German population, interviewing around 22,000 individuals living in 12,000 households across Germany every year (for details, see Wagner, Frick, and Schupp 2007). It started in 1984 in West Germany and after German reunification in 1990 included East Germany.

The SOEP collects a wealth of information about respondents' demographics, health, family composition, economic conditions, labor market outcomes, subjective well-being, preferences, and, last but not least, per- 
sonality traits, making it a very attractive data source for our analysis. The SOEP interviews all members of an eligible household aged 17 or above at the moment of the first interview and tracks all members even if they leave their original household. This feature allows us to not only match information on parental employment with information about offspring personality but also follow parents and children after they change household, for reasons that may include both nest-leaving of children and divorce of parents. Moreover, the SOEP administered to respondents a comprehensive big five personality questionnaire in three waves $(2005,2009$, and 2013), allowing us to carry out a longitudinal analysis.

Our working sample is constructed as follows. We pool the 2005 and 2009 samples, which we consider as our baseline interviews, and respectively track individuals up to their 2009 or 2013 4-year follow-up interviews. We consider only respondents whose baseline interview takes place within the impressionable years, in other words, those aged 17-25 at baseline and whose fathers are aged below 63-the early-retirement age in Germanyat baseline. We restrict our sample to consider only fathers who are present in the survey throughout the 4 years between the baseline and follow-up interviews and who work as employees in a private firm at baseline, since unemployment is more rare among public employees and among the self-employed. ${ }^{7}$ Although these criteria for sample selection are quite restrictive, we believe that they help us narrow down our sample to consider only those truly at risk of experiencing unemployment, increasing internal validity. We also drop individuals whose mothers are not in the survey, as our model makes use of information on mothers as well. After dropping observations with missing values in the children, mothers, and fathers covariates included in the analysis - listed in table $1^{8}$ - our final sample consists of 878 respondents, 59.6 percent of which belong to the 2005 baseline sample and 40.4 percent to the 2009 baseline sample. ${ }^{9}$ Descriptive statistics for the variables used in the analysis - measured at baseline-are reported in table 1 , while descriptive statistics for the variables measuring changes between baseline and follow-up are reported in table 2 .

Our outcome variables are individuals' big five personality factors: openness, conscientiousness, extraversion, agreeableness, and neuroticism. These are measured in the SOEP by a short but well-established personality questionnaire, unaltered across different waves of the survey and reported in table A2 (tables A1-A4 are available in the appendix). Respondents were

\footnotetext{
${ }^{7}$ Needless to say, we focus only on fathers whose children are observed at both the baseline and the follow-up interviews. This is eased by the fact that the SOEP also longitudinally tracks individuals who leave the original household, with limited attrition.

${ }^{8}$ Our models control for dummies for sector of employment of the father (two-digit International Standard Classification of Occupations codes), the regional level of unemployment at the time of the baseline interview, and regional dummies. Because of small sample size by region, we have aggregated Hamburg, Mecklenburg-Vorpommern, and SchleswigHolstein; Niedersachsen and Bremen; and Saarland and Rheinland-Pfalz. The full list of covariates is reported in the note for table 5 .

${ }^{9}$ More details on sample selection are reported in the appendix (available online). We do not detect significant differential effects of unemployment by baseline survey year, and therefore we pool the two samples throughout the analysis.
} 
TABLE 1

Descriptive Statistics Part 1: Baseline Covariates $(N=878)$

\begin{tabular}{lrr}
\hline & Mean & SD \\
\hline Offspring controls: & & \\
Female & .465 & .499 \\
Age & 20.657 & 2.456 \\
Immigrant & .050 & .218 \\
Firstborn child & .065 & .247 \\
Has siblings & .888 & .315 \\
Poor health & .038 & .190 \\
Life satisfaction & 7.428 & 1.567 \\
Employed & .606 & .489 \\
Unemployed & .040 & .196 \\
In education & .327 & .469 \\
Total household earnings $(€ 1,000)$ & 23.998 & 5.310 \\
Mother controls: & & \\
Age & 47.337 & 4.769 \\
Years of education & 12.258 & 2.466 \\
Immigrant & .074 & .264 \\
Poor health & .116 & .321 \\
Life satisfaction & 7.051 & 1.688 \\
Does not live with the offspring & .161 & .367 \\
Never unemployed before baseline & .546 & .498 \\
Unemployed at baseline & .033 & .179 \\
Father controls: & & \\
Age & 49.724 & 4.994 \\
Years of education & 12.455 & .622 \\
Immigrant & .078 & .269 \\
Poor health & .124 & .330 \\
Life satisfaction & 6.945 & .745 \\
Does not live with the offspring & .179 & .383 \\
Never unemployed before baseline & .639 & .481 \\
Employed in firm with $\leq 200$ employees & .511 & .500 \\
ln(labor earnings) & 10.574 \\
Tenure in the firm & 15.549 & .746 \\
Homeowner & .622 & .485 \\
Living in urban area & & \\
\hline & & .749 \\
& &
\end{tabular}

presented with a list of 15 statements (three for each trait) and were asked to rate how much they agreed with each of these statements on a sevenpoint Likert scale. As in Caliendo, Fossen, and Kritikos (2014), we treat the response scales cardinally and compute respondents' scores for each personality trait by simply averaging the scores from the three different statements referring to that factor and standardizing the resulting measure to have 0 mean and unit variance in the final sample. Therefore, descriptive statistics for personality variables are not shown in table 1 , but we report the densities of baseline and follow-up personality of offspring in figure 1, distinguishing between offspring experiencing and not experiencing paternal unemployment.

As highlighted by Borghans et al. (2008a, 2011), the simplicity of this measurement approach is not exempt from critiques. In fact, while variables such as height or weight can be measured directly, this is not true for personality, which must be inferred from responses to personality questionnaires like the one we use. This process is inevitably affected by mea- 
TABLE 2

Descriptive Statistics Part 2: Changes in Main Covariates between BaSEline AND Follow-UP $(N=878)$

\begin{tabular}{lrr}
\hline & Mean & SD \\
\hline Offspring: & .259 & .438 \\
Not employed at baseline, employed at follow-up & .033 & .179 \\
Not unemployed at baseline, unemployed at follow-up & .232 & .423 \\
In education at baseline, not in education at follow-up & 4,932 & 5,132 \\
Change in total household earnings $(€ 1,000)$ & .075 & .264 \\
Mother: & .103 & .303 \\
Experienced unemployment between baseline and follow-up & .026 & 1.709 \\
Not in poor health at baseline, in poor health at follow-up & .259 & .438 \\
Change in life satisfaction & .088 & .283 \\
Living with offspring at baseline, not living with offspring at follow-up & .084 & .278 \\
Father: & .093 & 1.690 \\
Experienced unemployment between baseline and follow-up (DadU) & .434 \\
Not in poor health at baseline, in poor health at follow-up & .252 & .42 \\
Change in life satisfaction & & \\
Living with offspring at baseline, not living with offspring at follow-up & & \\
\hline
\end{tabular}

surement error. For instance, as suggested by Piatek and Pinger (2015), treating personality items cardinally can distort results if the Likert scale used has a limited support or the distributions of the answers show high kurtosis. Furthermore, Almlund et al. (2011) highlight the fact that cognitive skills and other noncognitive traits and attitudes may also influence the answers to the personality questions, confounding the interpretation of the personality scores obtained in this simple way. On the one hand, there is not much we can do to address this latter problem, since contemporaneous or predetermined measures of cognitive abilities and other noncognitive traits are not available for the SOEP waves that we exploit. Hence, the interpretation of our results must take into consideration the fact that the personality scores we use also reflect the indirect influence that cognitive and other noncognitive skills may have had on respondents' answers to the personality questions. On the other hand, to check the robustness of our results to problems related with the ordinal versus cardinal treatment of the answers to personality items, we run a five-factor confirmatory factor analysis (CFA) on the personality items and extract the latent scores for each factor. Differently from our simple methodology, which gives equal loadings to each item related to a given factor, CFA estimates the loading of each of the items from the data, allowing for more flexibility. ${ }^{10}$ It turns out that the correlation between our simple average scores and the latent scores obtained via factor analysis is always around 0.9 , and results of all the analyses are quantitatively and qualitatively similar when we use either of the two measures. Given the simpler nature of the measures obtained by averaging, we prefer to stick to these ones throughout the analysis.

Following Boyce et al. (2015), we describe paternal unemployment - our treatment - with a dummy variable for whether the respondent's father

${ }^{10}$ Like Caliendo, Fossen, and Kritikos (2014), we have also carried out exploratory factor analysis. Using oblique promax rotation and retaining items with loadings higher than 0.3 , we fully confirm the five-factor model. 


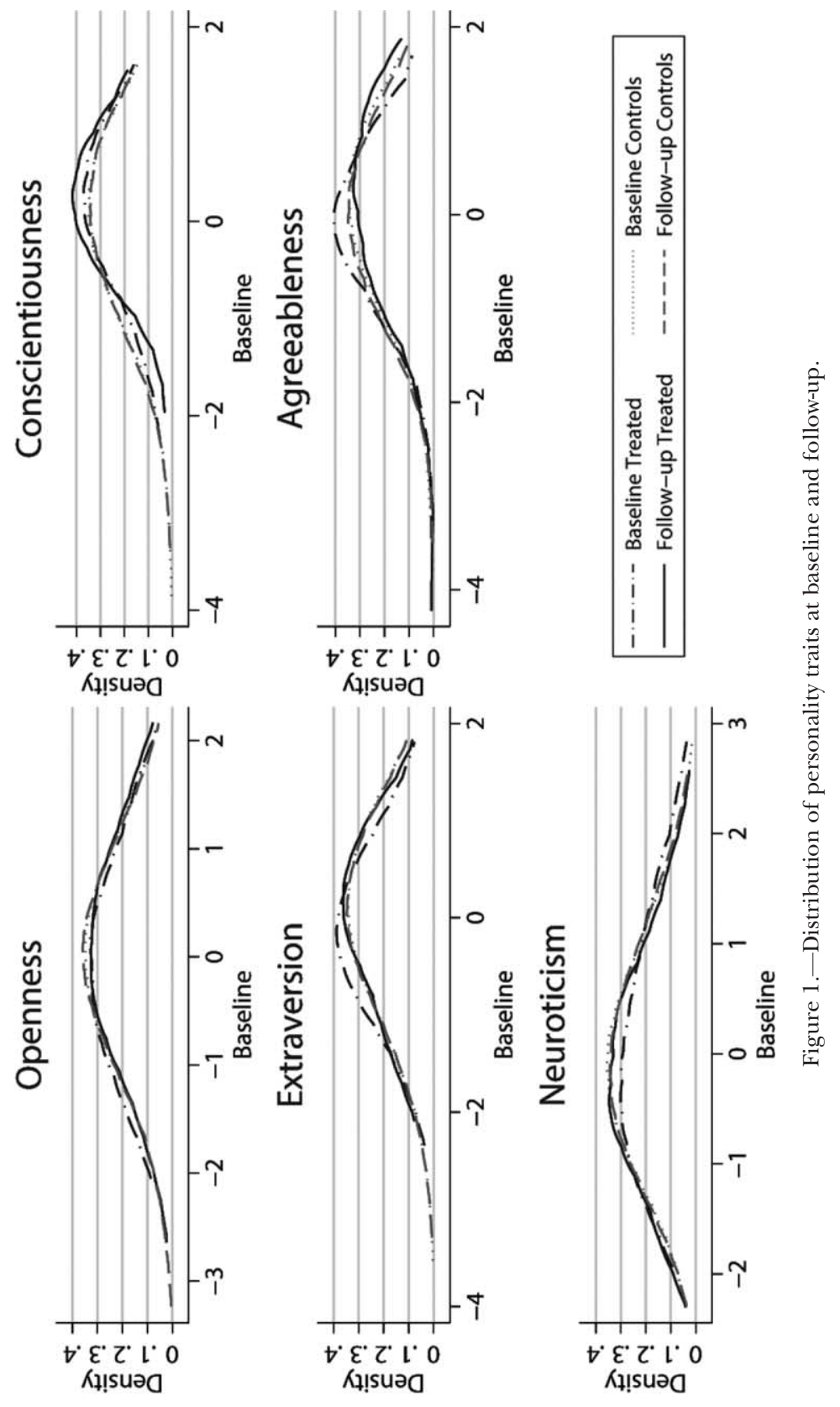


reports to be unemployed in any SOEP interview between the baseline (2005 or 2009) and the follow-up (2009 or 2013, respectively). Looking at table 1 , we see that 8.8 percent of respondents' fathers (that is, 77 fathers) have experienced unemployment between the baseline and followup interviews. ${ }^{11}$ Since both our sample and the number of treated fathers in it are small, we use robust regression and a simulation exercise to dispel the concern that our results may be due only to the presence of few outliers.

To gain a better understanding about the characteristics of fathers exposed or not exposed to unemployment, in table 3 we report mean values of several paternal characteristics by treatment group. Results point to negative selection into unemployment, as fathers experiencing unemployment are on average 2.3 years older, have 1.1 less years of education, are 16.3 percentage points more likely to be in poor health, have lower life satisfaction, and are 17.4 percentage points less likely to live with their child. Furthermore, their previous labor market career was also different, as they are 31.6 percent more likely to have ever experienced unemployment before the baseline interview (when they were employed), are more likely to work in smaller firms, have lower earnings and lower tenure, and are less likely to be a homeowner (a proxy for wealth). We have also tested for differences in fathers' personality at baseline (not reported to save space), and we find that those who will experience unemployment have a significant 0.40 standard deviations higher level of neuroticism with respect to the control group. ${ }^{12}$

Table 4 instead reports the differences in children's personality by paternal unemployment. In spite of the negative selection of fathers into unemployment, we do not detect any statistically significant difference in baseline personality among the two groups of children. In fact, the two groups of children look well balanced not only in terms of their own personality: we have tested for differences in other child-level baseline covariates, including age, gender, immigrant status, family composition, poor health, life satisfaction, and employment status, and we detect a statistically significant difference only for age, which is marginally higher among treated kids, and life satisfaction, which is instead lower in the treated group. ${ }^{13}$

\footnotetext{
11 Unfortunately, we do not have precise information about the duration of unemployment, as the self-reported spell data available in the SOEP are retrospective and may be severely affected by recall bias. Therefore, we use this information only in an extension. Additionally, we counted the number of interviews in which respondents report being unemployed, but there is very little variation in this variable. We also distinguished between different unemployment causes (see, e.g., Kassenboehmer and Haisken-DeNew 2009; Marcus 2013), such as layoffs, resignations, and plant closures, but our sample is too small to see enough of each of them (e.g., we observe only 12 instances of plant closure-induced unemployment).

12 We tested for difference in maternal characteristics as well. As expected under assortative matching in the marriage market, we find that mothers of offspring whose fathers experience unemployment are also negatively selected. Results are not reported to save space but are available from the authors.

${ }_{13}$ Results are not reported to save space but are available on request from the authors.
} 
TABLE 3

Mean of Selected Father Controls at Baseline by Paternal Unemployment

\begin{tabular}{|c|c|c|}
\hline & $\begin{array}{l}\text { Mean Employed } \\
\text { Father }\end{array}$ & $\begin{array}{l}\text { Unemployed/ } \\
\text { Employed Father }\end{array}$ \\
\hline Age & 49.519 & $\begin{array}{l}2.338 * * * \\
(.636)\end{array}$ \\
\hline Years of education & 12.547 & $\begin{array}{c}-1.098 * * * \\
(.225)\end{array}$ \\
\hline Immigrant & .071 & $\begin{array}{l}.020 \\
(.034)\end{array}$ \\
\hline Poor health & .110 & $\begin{array}{l}.163^{* * * *} \\
(.052)\end{array}$ \\
\hline Life satisfaction & 7.054 & $\begin{array}{c}-1.236^{* * * *} \\
(.264)\end{array}$ \\
\hline Does not live with the offspring & .164 & $\begin{array}{l}.174^{* * * *} \\
(.056)\end{array}$ \\
\hline Never unemployed before baseline & .667 & $\begin{array}{c}-.316^{* * * *} \\
(.057)\end{array}$ \\
\hline Employed in firm with $\leq 200$ employees & .486 & $\begin{array}{l}.294 * * * \\
(.051)\end{array}$ \\
\hline $\ln$ (labor earnings) & 10.623 & $\begin{array}{c}-.557 * * * \\
(.091)\end{array}$ \\
\hline Tenure in the firm & 16.134 & $\begin{array}{c}-6.668 * * * \\
(1.206)\end{array}$ \\
\hline Homeowner & .762 & $\begin{array}{c}-.177 * * * \\
(.058)\end{array}$ \\
\hline Lives in urban area & .631 & $\begin{array}{c}-.098^{*} \\
(.059)\end{array}$ \\
\hline
\end{tabular}

Note.--Robust standard errors are in parentheses.

$* p<.1$.

$* * * \quad p<.01$.

Results are different, however, when we repeat this exercise looking at differences in follow-up personality of children, as we see that treated children have a significant 0.29 standard deviations higher level of conscientiousness. We obtain similar results when we test the significance of differences in the whole distributions of personality traits between treated and control offsprings, both at baseline and at the follow-up (see fig. 1). Using Kolmogorov-Smirnov tests, we reject only that the distribution of followup conscientiousness differs between groups $(p=.032)$. So far, our descriptive analysis suggests that paternal unemployment may have a beneficial effect on the personality of children, as it makes them more conscientious. The econometric analysis introduced in the next section aims at verifying the robustness of this bivariate association.

\section{Empirical Methodology}

We frame the identification problem in terms of potential outcomes. Our setup is such that we observe individuals for two time periods, pre- and posttreatment, respectively defined as $t=0$ and $t=1$. Our treatment is defined by the dummy variable $\operatorname{DadU}_{i}$, which indicates whether the father of child $i$ experiences unemployment between $t=0$ and $t=1$. 
TABLE 4

Mean Offspring Personality Traits at Baseline and Follow-up by Paternal Unemployment

\begin{tabular}{lcc}
\hline & Mean Employed Father & $\begin{array}{c}\text { Unemployed/ } \\
\text { Employed Father }\end{array}$ \\
\hline Baseline: & .002 & -.024 \\
Openness & -.011 & $(.121)$ \\
Conscientiousness & .010 & $(.115)$ \\
Extraversion & .008 & -.111 \\
Agreeableness & & $(.107)$ \\
Neuroticism & -.007 & -.091 \\
Follow-up: & & $(.110)$ \\
Openness & -.006 & .086 \\
Conscientiousness & & $(.136)$ \\
Extraversion & -.025 & .068 \\
Agreeableness & .002 & $(.125)$ \\
Neuroticism & & $.290^{* * *}$ \\
& & $(.099)$ \\
& & -.0095 \\
& & $(.114)$ \\
& & .107 \\
& & $(.130)$ \\
& & -.097 \\
& & $(.120)$ \\
\hline
\end{tabular}

Note.-Robust standard errors are in parentheses. $* * * p<.01$.

We define the vectors of the five observed personality traits of child $i$ at $t=0$ and $t=1$ as $Y_{i}^{0}$ and $Y_{i}^{1}$, respectively. On the other hand, we let $Y_{1 i}^{1}$ and $Y_{0 i}^{1}$ be the vectors of the five potential $t=1$ personality traits of child $i$ in the case in which the father does or does not experience unemployment between the baseline and follow-up interview, respectively. We are interested in the identification of the average treatment effect on the treated (ATT), which is defined in terms of potential outcomes at $t=1$ as $E\left[Y_{1 i}^{1}-Y_{0 i}^{1} \mid \operatorname{DadU}_{i}=1\right]$ and measures the average effect of paternal unemployment on children's personality for children whose fathers have experienced unemployment.

Of course, the unconditional comparison of $t=1$ personality of treated and untreated children, which we have carried out in the previous section, is informative about the ATT only if $\mathrm{DadU}_{i}$ can be considered to be as good as randomly assigned. Unfortunately, the evidence provided in tables 3 and 4 and discussed in the previous section shows that - even if treated and control children are well balanced in terms of their own baseline personality traits and other observable characteristics - there are substantial differences in predetermined observable characteristics between the fathers of the two groups of children. In particular, negative selection of fathers into unemployment implies that the unconditional comparison of children's personality is biased toward finding negative differences in 
personality between treated and control children if personality is positively associated with parental background (see Eisenberg et al. 2014). This would run against our descriptive finding of a positive effect of paternal unemployment on children's conscientiousness. We can instead rule out reverse causality issues, since the treatment predates the followup personality assessment.

We take advantage of the longitudinal nature of our data to estimate value-added models of personality (see Todd and Wolpin 2003; Guarino, Reckase, and Wooldridge 2014). These models exploit the information about $Y_{i}^{0}$, a vector of children's personality traits measured at $t=0$, before the treatment took place, as a "sufficient statistic" for all predetermined unobserved variables that may affect follow-up personality and are not included in the model. Formally, we estimate the following system of five linear equations, one for each follow-up personality trait, $Y_{i j}^{1}, j=$ $1, \ldots, 5$ :

$$
Y_{i j}^{1}=\alpha_{j}+\beta_{j} \operatorname{DadU}_{i}+\delta_{j}^{\prime} Y_{i}^{0}+\gamma_{j}^{\prime} X_{i}^{0}+\varepsilon_{i j}, j=1, \ldots, 5,
$$

where $X_{i}^{0}$ is the vector of baseline covariates listed in tables 1 and 2, sector of employment of the father, a dummy for belonging to the 2009 baseline sample, the regional unemployment rate at baseline, regional dummies, and a vector of maternal and paternal baseline personality traits. Finally, $\varepsilon_{i j}$ is an error term, which we allow to be correlated across equations.

By allowing the coefficient for the lagged outcome to be different from 1 , value-added specifications leave more flexibility than first-differences (or "diff-in-diffs") models. In addition, the absence of statistically significant differences in baseline personality between treated and untreated offspring also points against using first-differences models.

Todd and Wolpin (2003) derive the (undoubtedly stringent) assumptions that relate reduced-form value-added specifications such as the one described in equation (1) to a linear structural model of cognitive skills formation. Their work has been extended by Cunha and Heckman (2008) and Cunha, Heckman, and Schennach (2010) to also consider the production of noncognitive skills and nonlinear models with endogenous inputs. In their setup, OLS estimation of the reduced-form model in equation (1) is inconsistent because of correlation between the lagged outcome and the error term of the structural model. However, according to the simulation study carried out by Guarino, Reckase, and Wooldridge (2014), this is not a first-order problem for the identification of the ATT of paternal unemployment. In fact, Guarino, Reckase, and Wooldridge (2014) show that by including the baseline level of the outcome the dynamic OLS specification of value-added models is very effective at controlling for several sources of unobserved heterogeneity, and it performs better than other estimators derived on the basis of structural modeling considerations that draw attention to second-order identification concerns (e.g., endogenous lags). 
On the basis of these considerations, we estimate the five-equation system described in equation (1) via OLS, and we further dispel concerns related with the endogeneity of the lagged outcome by carrying out a simulation exercise, where we show that our estimated effect of DadU is robust even when we introduce different degrees of positive or negative correlation between the lagged outcome and the error term of the model. ${ }^{14}$ As a further robustness test, we also use the subsample of offspring that we observe in three instances (2005, 2009, and 2013) and instrument baseline 2009 personality with its lagged value, measured in 2005, as is commonly done in value-added models. Although the resulting sample size shrinks dramatically (we end up having only 150 observations), the estimated effects are comparable between OLS and instrumental variables (IV), as well as with the one estimated with OLS in the full sample.

Consequently, as stated in Angrist and Pischke (2008, ch. 5), identification of the ATT from model (1) relies on the following assumption:

$$
E\left[Y_{0 i}^{1} \mid \operatorname{DadU}_{i}=1, Y_{i}^{0}, X_{i}^{0}\right]=E\left[Y_{0 i}^{1} \mid \operatorname{DadU}_{i}=0, Y_{i}^{0}, X_{i}^{0}\right],
$$

which implies that, conditional on the baseline covariates and the baseline personality traits of the children, we can take the (observed) average follow-up personality scores for the control group as a plausible average counterfactual outcome for the treatment group, had it not experienced the treatment. Under assumption (2), in each equation of model (1) the coefficient $\beta_{j}$ identifies the ATT of paternal unemployment on the $j$ th personality trait.

It is worth remarking that the set of baseline covariates included in $X_{i}^{0}$ is unusually rich, as it includes a comprehensive set of paternal characteristics and in particular a thorough description of paternal labor market history (earnings, tenure, firm size, occupation, previous experience of unemployment) and characteristics of the mother, the family of origin, and the child. Together with indicators of baseline personality of both the parents and the child, we do believe that these are sufficient to grant conditional independence of the treatment and potential outcomes.

In light of the wide evidence about the stability (i.e., intraindividual changes in personality traits in response to life events) of personality traits (for recent evidence, see Cobb-Clark and Schurer 2012), we consider specification (1) to be demanding enough so that any effect that should survive could be interpreted as causal. Nevertheless, we also carry out a set of tests aimed at gauging the robustness of our results to selection on unobservables, based on the estimators proposed by Altonji, Elder, and Taber (2005) and Oster (2017), described below. Finally, we also show that our

\footnotetext{
${ }^{14}$ We always use heteroskedasticity-robust standard errors. Since the error terms associated to the different traits can be correlated, we also jointly estimate the system using seemingly unrelated regressions. However, we find no significant change in the standard errors with respect to estimation equation by equation. This is not surprising, as all models include the same explanatory variables.
} 
estimates are qualitatively similar when we use semiparametric estimators based on propensity score weighting (see Hirano, Imbens, and Ridder 2003) and entropy balance weighting (see Hainmueller 2012).

\section{Results}

\section{A. Main Results}

Table 4 reports our main results. In each column we report the ATT of paternal unemployment on each of the big five personality traits, estimated as described in the previous section. The three columns report results when we progressively add a richer set of controls to the model. In particular, column 1 includes only the baseline personality traits of the child; column 2 adds wave dummies, regional dummies, children's and parents' baseline covariates (listed in table 1), and parental baseline personality traits; and column 3 also includes changes in offspring's and parents' covariates (listed in table 2).

Our main result is that paternal unemployment increases children's level of conscientiousness by 0.229 to 0.310 standard deviations, depending on the specification adopted. In spite of our relatively small sample size, the estimated effect is strongly significant from a statistical point of view, as the $p$-values of the estimated effects are always below $.01 .^{15} \mathrm{In}$ addition, the estimated effect is also large in magnitude. For instance, looking at the fathers' sample, we observe a raw difference in conscientiousness of similar magnitude between fathers with secondary education or more than secondary education. The result confirms the descriptive evidence presented in the previous section and is qualitatively and quantitatively robust to the inclusion of a progressively more demanding set of controls. We also find that paternal unemployment reduces children's neuroticism by -0.138 to -0.222 standard deviations, but this effect is only marginally significant, and its magnitude is more dependent on the set of controls included in the model. The other personality traits are instead not affected by the experience of paternal unemployment.

All in all, our main results suggest that paternal unemployment improves children's personality. This evidence is consistent with the psychological literature on the effects of negative events on personality (for a review,

\footnotetext{
${ }^{15}$ In our exercise, we are testing the effect of paternal unemployment on five outcomes. Let the family-wise error rate (FWER) be the probability of rejecting at least one true null hypothesis, that is, of making at least one type I error. The Bonferroni correction is the most conservative method to control for the FWER. In our case, this method suggests that to control for FWER at a level of significance $\alpha$ one should reject the null hypothesis only if the $p$ value is smaller than $\alpha / 5$. Setting $\alpha=0.05$, the Bonferroni correction would lead us to reject a null hypothesis with a FWER at 0.05 only when $p<.01$. In our more comprehensive specification (see col. 3), the $p$-value for conscientiousness is equal to .009 , below .01 . Hence, our main results are significant even with the more conservative method to carry out multiple testing. Other less conservative methods lead to the same conclusion. For instance, for conscientiousness we obtain $p<.01$ using the step-down procedure suggested by Romano and Wolf (2005).
} 
see Seery 2011), which has shown that, while experiencing no or a high level of adversity has negative consequences on the development of the individual, moderate levels of adversity, such as paternal job loss, can actually be beneficial by building resilience. It is also worth noticing that, as we observe only two measures of personality traits with a 4-year gap between them, we can estimate only a short-term effect of unemployment experienced between the two waves and cannot assess whether these effects would persist in the long run.

As an extension, we have carried out a parallel analysis for the effects of maternal unemployment. After applying the same sample selection criteria used to analyze fathers' unemployment - that is, by considering only offspring whose mothers were working as private employees at baseline-we are left with a much smaller sample of only 579 observations. We do not detect any significant effect of maternal unemployment on offspring personality (detailed results are available from the authors). A likely explanation for the difference in the effects of maternal and paternal unemployment could be that mothers' lower attachment to the labor market makes their unemployment episodes less salient for offspring. Yet this conclusion should be taken as speculative at best.

\section{B. Robustness Tests}

Before presenting results from subgroup analysis, we describe a large battery of tests that we have carried out to verify the robustness of our main results. As a first robustness check, we use robust regressions and run a simulation exercise to verify that our estimated effects are not due to outliers - a relevant concern given that our sample is relatively small. On the one hand, robust regression is an alternative to least squares that allows us to detect and give low weight to outliers in the estimation of a regression model. On the other hand, to assess that no small group of observations is the main driver of our results, we also randomly drop 1 percent of the sample and reestimate the model 1,000 times. We drop only 1 percent of the sample in each iteration to avoid losing precision. For conscientiousness - the only trait for which we estimate a consistently significant ATT and considering the model with all covariates, our robust regression coefficient is equal to 0.27 ( $p=.025)$-indistinguishable from our baseline estimate. Using our simulation strategy, the coefficient on DadU ranges between a minimum of 0.24 and a maximum of 0.33 and is not statistically significant in less than 1 percent of the repetitions. Therefore, both tests lead us to reject the possibility that our main effect is driven by outliers. ${ }^{16}$

Second, we also use simulations to dispel concerns related with correlation between the lagged outcome and the error term, which could make OLS estimates of the effect of paternal unemployment in our value-added

\footnotetext{
${ }^{16}$ Results for other outcomes and specifications are also robust and are available from the authors.
} 
model inconsistent. Again, we focus on conscientiousness and the model with all covariates, but results for other outcomes and specifications are also robust and available from the authors. We proceed as follows: first, we simulate a random normal error term $e_{i}$ that has the same mean and standard deviation as the estimated residual from model (1). Second, we introduce correlation between the error term $e_{i}$ and the baseline value of the outcome - conscientiousness - by computing a fictitious baseline outcome $Y_{i}^{0}=Y_{i}^{0}+\omega \times e_{i}$. We allow $\omega$ to vary between -1 and 1 in steps of 0.2 , therefore allowing for different degrees of correlation between $Y_{i}^{0}$ and $e_{i}$. Third, for each value of $\omega$, we generate the simulated outcome $Y_{i}^{1}$ using $Y_{i}^{0}$, our observed data for the other covariates, the estimated coefficients from the observed data in model (1), and the simulated error term $e_{i}$. We repeat this procedure 1,000 times for each value of $\omega$ and reestimate model (1) each time. For each value of $\omega$, the $2.5,50$ th, and 97.5 percentiles of the empirical distribution of the coefficient of DadU are reported in table A3. For all values of $\omega$, the median is close to the value of the coefficient in the original data, and the empirical confidence interval at the 5 percent level of confidence does not include 0 , leading us to conclude that our estimated effect is robust to the presence of an arbitrary degree of correlation between the baseline outcome and the error term. As an additional robustness test for this potential issue, we use the subsample of offspring that we observe in three instances (2005, 2009, and 2013) and instrument baseline 2009 personality with its lagged value, measured in 2005, as is commonly done in value-added models (Andrabi et al. 2011). Although the resulting sample size shrinks dramatically (we end up having only 150 observations), the estimated effects are comparable between OLS and IV, as well as with the one estimated with OLS in the full sample. ${ }^{17}$

Next, although our estimates control for a very rich set of observables, it could still be the case that other unobserved characteristics of the child, the mother, or the father that are correlated with selection into unemployment could be driving our results. Hence, following Altonji, Elder, and Taber (2005) and Nunn and Wantchekon (2011), we use selection on observables to assess the potential bias of our estimates presented in table 4 from unobservable omitted variables. To do so, we compare the effects estimated in column $1, \hat{\beta}^{\mathrm{R}}$, that control only for a restricted set of covariates (children's baseline personality), and column $4, \hat{\beta}^{\mathrm{F}}$, that include the full set of controls, by computing the following ratio: $\hat{\beta}^{\mathrm{F}} /\left(\hat{\beta}^{\mathrm{R}}-\hat{\beta}^{\mathrm{F}}\right)$. This ratio is informative about how strong selection on unobservables should be, with respect to selection on observables, to entirely account for the estimated effects. On the one hand, the larger $\hat{\beta}^{\mathrm{F}}$ is, the larger the effect that needs to be explained by selection on unobservables. On the other hand, the smaller the denominator, the less our estimate is affected

${ }^{17}$ Results are available from the authors. 
by selection on observables and the stronger selection on unobservables needs to be to explain away the entire effect. A negative ratio would instead mean that, if anything, the estimated effect is biased downward by selection on unobservables, so long as selection on observables and selection on unobservables are positively correlated - a tenable assumption. For conscientiousness, we compute a ratio equal to -3.826 . Hence, if anything, the estimated effect is biased downward by selection on unobservables, putting us in a safe position. ${ }^{18}$

In a recent study, Oster (2017) extends the arguments of Altonji, Elder, and Taber (2005) about estimating the degree of selection on unobservables that would be required to drive the ATT to 0 (called $\delta$ ) to consider both coefficient movements and movements in $R^{2}$ values after the inclusion of controls. In fact, coefficient changes are informative about omitted variables bias only if these are rescaled by the movement in $R^{2}$, in other words, by the additional fraction of variance of the outcome that is explained by the included controls. If this fraction is large, then the remaining variance of the outcome that can be explained by selection on unobservables, and thus bias coefficients, is negligible. Contrarily, changes in coefficients are less informative about the effects of unobservables' selection if this fraction is small. To apply this method, we need to set a maximum attainable value of the $R^{2}, R_{\max }$, that indicates the maximum share of variance of the outcome that could be explained by any set of observable and unobservable covariates. Assuming that there is at least some random noise in empirical data, a value of $R_{\max }=1$ is viewed by Oster as too conservative. We follow the rule proposed by Oster of setting $R_{\max }$ equal to 1.3 times the $R^{2}$ of the model that includes all covariates. ${ }^{19}$ In our case, this implies setting $R_{\max }=0.44$ for conscientiousness and $R_{\max }=0.42$ for neuroticism. For conscientiousness, we compute that $\delta_{0.44}=-103.27$. Consistent with the estimate Antonji ratio, this negative value suggests that, if anything, selection on unobservables is biasing our estimates downward. Indeed, our results would be robust even with higher values of $R_{\max }$. For instance, setting $R_{\max }=0.9$ would still leave us with $\delta_{0.9}=-19.49 .{ }^{20}$

Additionally, to verify the robustness of our main results to the linear parametric specification of our model, we also exploit semiparametric estimation methods based on adjusted propensity score weighting (see Hirano, Imbens, and Ridder 2003) and entropy balance weighting (see Hainmueller 2012). The former method uses Horowitz-Thompson weights estimated on the basis of a propensity score to reweight the data and achieve balancing on the observables. Since this method relies on an estimated

18 The ratio is equal to -2.643 for neuroticism.

19 This is computed by Oster as the value that would allow 90 percent of randomized control trial studies published in the top five economics journals between 2008 and 2013 to survive in rejection-of-zero tests like the one we are using.

${ }^{20}$ Even in this case, we compute a negative value of $\delta$ for neuroticism, since $\delta_{0.42}=-6.32$ and, in the extreme case where $R_{\max }=0.9, \delta_{0.9}=-1.06$. 
propensity score, it may fail to improve balancing in finite samples. The latter method instead overcomes this drawback by using a maximum entropy reweighting scheme that weighs each unit in the control group in such a way that the covariate distributions in the reweighted data have the same means as in the treatment group, thereby obtaining a reweighted sample that is perfectly balanced on the means of the included observable covariates, even in small samples. Obtaining similar results with OLS, propensity score weighting and entropy balance weighting should be reassuring about the robustness of our results to different parametric specifications of the model. Results that use the same controls included in column 3 of table 5-our most comprehensive specification-are reported in the first two columns of table A4 and portray a picture similar to the one reported

TABLE 5

MAin Results

\begin{tabular}{lccc}
\hline & $(1)$ & $(2)$ & $(3)$ \\
\hline Openness & .074 & .065 & .025 \\
& $(.104)$ & $(.115)$ & $(.118)$ \\
$\quad$ Altonji ratio & & & .523 \\
Conscientiousness & $.229 * * *$ & $.269 * * *$ & $.310^{* * *}$ \\
& $(.083)$ & $(.092)$ & $(.094)$ \\
$\quad$ & & -3.826 \\
Altonji ratio & .023 & .031 & .007 \\
Extraversion & $(.107)$ & $(.118)$ & $(.118)$ \\
& & & .469 \\
Altonji ratio & .142 & .085 & .077 \\
Agreeableness & $(.110)$ & $(.111)$ & $(.111)$ \\
& & & 1.167 \\
Altonji ratio & -.138 & $-.202 *$ & $-.222^{* *}$ \\
Neuroticism & $(.101)$ & $(.111)$ & $(.111)$ \\
& & & -2.643 \\
Altonji ratio & Yes & Yes & Yes \\
Offspring baseline personality & No & Yes & Yes \\
Offspring's and parents' baseline covariates & No & Yes & Yes \\
Parents' baseline personality & No & No & Yes \\
Changes in offspring's and parents' covariates & 878 & 878 & 878 \\
Observations & &
\end{tabular}

Note.- The table reports the effect of DadU on each personality trait. Controls included in each model are listed at the bottom of the table. Offspring baseline covariates: gender, age, immigrant status, birth order, number of siblings, health status, life satisfaction, employment status. Father baseline covariates: age, immigrant status, health status, life satisfaction, years of education, present and past unemployment status, living in same household as offspring. For fathers, we also include employment sector, firm size, log labor earnings, tenure in the firm. Household baseline covariates: total household earnings, homeownership, living in urban or rural area, regional fixed effects, year fixed effects, regional unemployment. Changes in offspring covariates: change in employment, unemployment and educational status, change in total household earnings. Changes in mother and father covariates: change in health status, change in life satisfaction, change in coresidence with offspring. For mothers we also include the experience of unemployment between baseline and follow-up. Equations for the different personality traits in each model are estimated jointly, using seemingly unrelated estimation. Robust standard errors are in parentheses.

$* p<.1$.

$* * p<.05$.

$* * * \quad p<.01$. 
in table 5. We still find a statistically significant positive effect of paternal unemployment on children's follow-up level of conscientiousness (although larger in magnitude), and we also still find a negative effect of paternal unemployment on neuroticism, but this effect is not significant when we use entropy balancing. Also in this case, the ATT on other personality traits is close to 0 in magnitude and not statistically significant.

As a further robustness check, we replicate our main analysis using personality scores obtained by extracting latent factors via a confirmatory factor analysis instead of using the raw means, as described in Section II. Results - presented in column 3 of table A4 - are qualitatively and quantitatively similar to those presented in table 5 .

In a final robustness test, we also verify that our results are not driven by the presence in our control group of both fathers that have been working throughout the period between the baseline and follow-up interview and fathers who have left the labor force by the follow-up interview for reasons that include retirement, disability, or others. To this end, we verify what happens when we (1) include a specific dummy for being out of the labor force by the follow-up (the effects of unemployment on both conscientiousness [coefficient: 0.28, SE: 0.09] and neuroticism [coefficient: -0.19 , SE: 0.11$]$ are unchanged, and the effect of inactivity is close to 0 and not significant on both conscientiousness and neuroticism) or (2) drop from our sample the 34 fathers who permanently left the labor force between the baseline and follow-up interview, for reasons that include retirement, disability, or others (the effect of unemployment on conscientiousness is unchanged [coefficient: 0.2, SE: 0.10], and the effect on neuroticism gets slightly smaller and has a $p$-value of .11 [coefficient: 0.19, SE: 0.12 ]).

\section{Discussion: Investigating Potential Mechanisms}

To understand the potential mechanisms behind our estimated effects, our final analysis investigates heterogeneous effects by subgroups of the population. We estimate heterogeneous effects with linear models akin to model (1) by interacting the treatment dummy with two dummies, one for each of the groups that we are interested in, and by excluding the constant from the model. Since this analysis aims only at explaining the mechanisms behind our main findings, we consider only conscientiousness and neuroticism. Unfortunately, we do not have enough power to test whether the effects are statistically different between groups. Therefore, results in this subsection should be taken as suggestive at best.

Since we find positive causal effects, we confidently rule out that these are a direct consequence of the economic and mental distress of unemployed fathers. Our most plausible remaining explanations are improved father-child interactions and psychological resilience to avoid falling into unemployment later on.

We first consider heterogeneous effects between offspring who are younger and older than 20 at baseline, the median age in the sample. On 
the one hand, younger offspring are the ones with whom fathers may interact more if unemployed, as they are less likely to be time-constrained by work. Younger offspring are also more likely to cohabit with fathers, but since only 17.8 percent of offspring do not cohabit with fathers at baseline we consider this as a second-order channel. ${ }^{21}$ On the other hand, older offspring are more likely to be employed and therefore more exposed to a direct threat of unemployment - and scared by its consequences.

Panel A of table 6 shows that-for conscientiousness-older offspring are indeed the sole group affected by paternal unemployment, suggesting that improved parent-child interactions are unlikely to be a plausible explanation behind our estimated positive effects. This hypothesis is further confirmed by results reported in panel B of table 6 , where we estimate heterogeneous effects for employed and unemployed offspring at baseline and find that - for conscientiousness - the first group is the only one for whom the effect is statistically significant. For neuroticism, we do not find evidence of heterogeneous effects.

Taken together, these pieces of evidence suggest that the effect we have detected on conscientiousness can be interpreted as a psychological coping device that mostly affects employed offspring, who face a direct risk of unemployment and may be more prone to improve their work attitude to not experience the negative consequences of unemployment demonstrated by their fathers.

Panels C, D, E, and F of table 6 investigate other potential mechanisms behind our results. In panel $\mathrm{C}$, we focus on gender differences in coping behavior. It is interesting to notice that the effects on both conscientiousness and neuroticism are larger in magnitude and statistically significant only for females. Although the effects are not statistically different by gender, these results suggest that our main results are mostly driven by women. This finding is rather surprising, given that several studies (Matud 2004; Stratta et al. 2012) find that males are generally better at coping with stressful events than females. On the other hand, panel D of table 6 shows a similar pattern as far as maternal employment status at baseline is concerned, since the effects are statistically significant only for the group of children whose mothers were employed..$^{22}$ This latter finding is also intriguing, as it may shed light on the mechanisms behind our main results. In fact, a potential interpretation of this finding is that unemployed fathers whose wives were employed at baseline may have had more time to search for an appropriate job, given the income support from their spouses, being thus more present in the family life while unemployed, with potentially positive effects on their children's personality. Finally, panels E and F of table 6 document that we do not find evidence of heterogeneous effects by parental education or length of paternal unemployment. Needless to say, several

\footnotetext{
21 We have also tried to estimate heterogeneous effects by coresidence status at baseline, but effects are similar and not statistically different between the two subsamples.

22 Even in this case, however, the differences in the effects are not statistically significant.
} 
TABLE 6

Heterogeneous EFFEcts

\begin{tabular}{|c|c|c|}
\hline & $\begin{array}{l}\text { Conscientiousness } \\
\text { (1) }\end{array}$ & $\begin{array}{c}\text { Neuroticism } \\
\text { (2) }\end{array}$ \\
\hline \multicolumn{3}{|l|}{ A. By offspring's age: } \\
\hline DadU: younger offspring (age < 20) & $\begin{array}{c}.196 \\
(.148)\end{array}$ & $\begin{array}{c}-.265 \\
(.179)\end{array}$ \\
\hline DadU: older offspring (age $\geq 20$ ) & $\begin{array}{l}.421 * * * \\
(.105)\end{array}$ & $\begin{array}{c}-.150 \\
(.131)\end{array}$ \\
\hline Difference $(p$-value $)$ & .192 & .595 \\
\hline \multicolumn{3}{|l|}{ B. By offspring's employment status: } \\
\hline DadU: employed offspring & $\begin{array}{l}.358^{* *} \\
(.104)\end{array}$ & $\begin{array}{c}-.134 \\
(.124)\end{array}$ \\
\hline DadU : not employed offspring & $\begin{array}{l}.192 \\
(.160)\end{array}$ & $\begin{array}{c}-.382 * \\
(.196)\end{array}$ \\
\hline Difference ( $p$-value) & .360 & .266 \\
\hline \multicolumn{3}{|l|}{ C. By offspring's gender: } \\
\hline DadU: male offspring & $\begin{array}{l}.231 * * * \\
(.129)\end{array}$ & $\begin{array}{r}-.083 \\
(.156)\end{array}$ \\
\hline DadU: female offspring & $\begin{array}{l}.377 * * * \\
(.122)\end{array}$ & $\begin{array}{l}-.375^{* * *} \\
(.144)\end{array}$ \\
\hline Difference ( $p$-value) & .468 & .491 \\
\hline \multicolumn{3}{|l|}{ D. By maternal employment status at baseline: } \\
\hline DadU: employed mother & $\begin{array}{l}.909 * * * \\
(.109)\end{array}$ & $\begin{array}{l}-.325^{* *} \\
(.131)\end{array}$ \\
\hline DadU: not employed mother & $\begin{array}{l}.322 * * \\
(.161)\end{array}$ & $\begin{array}{r}-.006 \\
(.184)\end{array}$ \\
\hline Difference $(p$-value $)$ & .864 & .131 \\
\hline \multicolumn{3}{|l|}{ E. By highest educational attainment of parents: } \\
\hline DadU: at least one parent has above high school degree & $\begin{array}{l}.284 * * * \\
(.147)\end{array}$ & $\begin{array}{c}-.263 \\
(.180)\end{array}$ \\
\hline DadU: no parent has above high school degree & $\begin{array}{l}.253 * * * \\
(.111)\end{array}$ & $\begin{array}{l}-.201 \\
(.133)\end{array}$ \\
\hline Difference ( $p$-value) & .399 & .777 \\
\hline \multicolumn{3}{|l|}{ F. Short- and long-term paternal unemployment: } \\
\hline Father short-term unemployed (<6 months) & $\begin{array}{l}.284 * * * \\
(.102)\end{array}$ & $\begin{array}{l}.122 \\
(.120)\end{array}$ \\
\hline Father long-term unemployed ( $\geq 6$ months) & $\begin{array}{l}.261 * * * \\
(.099)\end{array}$ & $\begin{array}{l}-.106 \\
(.131)\end{array}$ \\
\hline Difference ( $p$-value) & .856 & .165 \\
\hline Observations & 878 & 878 \\
\hline
\end{tabular}

Note.-The table reports the heterogeneous effects of DadU on conscientiousness and neuroticism. The effects are estimated by running a model interacting DadU with dummies for each group and omitting the constant (except for unemployment duration, where we consider the two durations as alternative treatments). The $p$-value for the significance of the difference in the effects across groups is also reported. The specification adopted is equal to the one shown in col. 3 of table 5 . The equations for the different personality traits are estimated jointly, using seemingly unrelated estimation. Robust standard errors are in parentheses.

$* p<.1$.

$* * \quad p<.05$.

$* * * \quad p<.01$.

other mechanisms can be at play to explain both our main results and results from subgroup analysis, such as children needing to provide financial support to their parent when their father becomes unemployed. Further research that uses more extensive data should investigate this important aspect. 


\section{Conclusions}

Using longitudinal data about the German population, we are the first to identify the effects of paternal unemployment on the big five personality traits during adolescence and early adulthood. Our estimates from valueadded models suggest that paternal unemployment has a surprisingly positive effect on children's personality, as it improves their conscientiousness and decreases their levels of neuroticism. Our results are robust to a large set of specification checks, including simulations for correlation between the baseline outcome and the error term and tests for selection on unobservables - which could make OLS estimation of the effect of paternal unemployment inconsistent in our value-added models. Since in the models of Heckman (2007) and Conti, Heckman, and Urzua (2010) conscientiousness affects the educational, labor market, and health behavior choices made by individuals, an increased level of conscientiousness at a young age might lead to a virtuous "self-productivity cycle," resulting in improved health and socioeconomic conditions throughout the life cycle. However, we would need data that cover a longer time period to understand whether the estimated effects are persistent or transitory.

Two aspects of our results are worth further discussion. First, it is not difficult to explain why we detect an effect of paternal job loss on conscientiousness and neuroticism of children exclusively. Indeed, among the big five dimensions, these two traits are the most related to children's work vision and the ability to deal with their uncertain future. Second, our findings are in line with several psychological studies (for a review, see Seery 2011) that show how experiencing moderate levels of adversity, such as paternal job loss, can be beneficial to the individual development by building resilience.

We investigate potential mechanisms that can explain our effects. In this respect, we show that - for conscientiousness - older and employed offspring are the ones for whom we detect positive and statistically significant effects of paternal unemployment. This result suggests that increased time spent by unemployed parents with their offspring is unlikely to be a mechanism at play. We are instead more prone to suggest that the negative scars that unemployment left on their fathers may have improved the work attitude of employed offspring, who want to avoid falling into unemployment themselves. We also find that the negative effect of paternal job loss on neuroticism is group specific, being mainly detected when focusing on females and children whose mothers are employed. Needless to say, further research that uses more extensive data should investigate this important aspect more in-depth.

\section{References}

Almlund, M., A. L. Duckworth, J. Heckman, and T. Kautz. 2011. "Personality, Psychology and Economics." In Handbook of the Economics of Education, vol. 4, edited by E. A. Hanushek, S. Machin, and L. Woessmann, 1-181. Amsterdam: Elsevier. 
Altonji, J. G., T. E. Elder, and C. R. Taber. 2005. "Selection on Observed and Unobserved Variables: Assessing the Effectiveness of Catholic Schools." J.P.E. 113 (1): 151-84.

Alwin, D. F. 1994. "Aging, Personality, and Social Change: The Stability of Individual Differences over the Adult Life Span." In Life-Span Development and Behavior, edited by D. L. Featherman, R. M. Lerner, and M. Perlmutter. Hillsade, NJ: Erlbaum.

Andrabi, T., J. Das, A. I. Khwaja, and T. Zajonc. 2011. "Do Value-Added Estimates Add Value? Accounting for Learning Dynamics.” American Econ. J.: Appl. Econ. 3 (3): 29-54.

Anger, S., G. Camehl, and P. Frauke. 2016. "Job Loss and Changes in PersonalityEvidence from Plant Closures.” Working paper, Leibniz Information Centre for Econ.

Angrist, J. D., and J.-S. Pischke. 2008. Mostly Harmless Econometrics: An Empiricist's Companion. Princeton, NJ: Princeton Univ. Press.

Barenbaum, N. B., and D. G. Winter. 2008. "History of Modern Personality Theory and Research." In Handbook of Personality: Theory and Research, edited by O. P. John, R. W. Robins, and L. A. Pervin, 3-26. New York: Guilford.

Barrick, M. R., and M. K. Mount. 1991. "The Big Five Personality Dimensions and Job Performance: A Meta-analysis.” Personnel Psychology 44 (1): 1-26.

Borghans, L., A. L. Duckworth, J. J. Heckman, and B. ter Weel. 2008a. "The Economics and Psychology of Personality Traits." J. Human Resources 43 (4): 9721059.

Borghans, L., B. H. Golsteyn, J. Heckman, and J. E. Humphries. 2011. "Identification Problems in Personality Psychology." Personality and Individual Differences 51 (3): 315-20.

Borghans, L., H. Meijers, and B. ter Weel. 2008b. "The Role of Noncognitive Skills in Explaining Cognitive Test Scores.” Econ. Inquiry 46 (1): 2-12.

Boyce, C. J., A. M. Wood, M. Daly, and C. Sedikides. 2015. "Personality Change Following Unemployment.” J. Appl. Psychology 100 (4): 991-1011.

Brunello, G., and M. Schlotter. 2011. "Non-cognitive Skills and Personality Traits: Labour Market Relevance and Their Development in Education and Training Systems.” IZA Working Paper no. 5743, Inst. Study Labor, Bonn.

Bucciol, A., B. Cavasso, and L. Zarri. 2015. "Social Status and Personality Traits." J. Econ. Psychology 51: 245-260.

Caliendo, M., F. Fossen, and A. S. Kritikos. 2014. "Personality Characteristics and the Decisions to Become and Stay Self-Employed." Small Bus. Econ. 42 (4): 787-814.

Christoffersen, M. N. 1994. "A Follow-up Study of Long-Term Effects of Unemployment on Children: Loss of Self-Esteem and Self-Destructive Behaviour among Adolescents." Child Development 4: 212-20.

Cobb-Clark, D. A., and S. Schurer. 2012. "The Stability of Big-Five Personality Traits.” Econ. Letters 115 (1): 11-15.

Coelli, M. B. 2011. "Parental Job Loss and the Education Enrollment of Youth." Labour Econ. 18 (1): 25-35.

Conti, G., J. Heckman, and S. Urzua. 2010. "The Education-Health Gradient." A.E.R. 100 (2): 234-38.

Costa, P. T., and R. R. McCrae. 1994. "Set like Plaster? Evidence for the Stability of Adult Personality." In Can Personality Change? edited by T. F. Heatherton and J. L. Weinberger, 21-40. Washington, DC: American Psychological Assoc.

Costa, P. T., R. R. McCrae, and D. Arenberg. 1980. "Enduring Dispositions in Adult Males." J. Personality and Soc. Psychology 38 (5): 793-800.

Cunha, F., and J. J. Heckman. 2008. "Formulating, Identifying and Estimating the Technology of Cognitive and Noncognitive Skill Formation." J. Human Resources 43 (4): 738-82. 
Cunha, F., J. J. Heckman, and S. M. Schennach. 2010. "Estimating the Technology of Cognitive and Noncognitive Skill Formation." Econometrica 78 (3): 883931.

Cutler, N. E. 1974. "Aging and Generations in Politics: The Conflict of Explanations and Inference." In Public Opinion and Political Attitudes, edited by A. R. Wilcox, 440-62. New York: Wiley.

Dennis, J. 1973. Socialization in Politics: A Reader. New York: Wiley.

Duncan, G. J., C. J. Dowsett, A. Claessens, et al. 2007. "School Readiness and Later Achievement." Developmental Psychology 43 (6): 1428-46.

Easton, D., and J. Dennis. 1969. Children in the Political System: Origins of Political Legitimacy. New York: McGraw-Hill.

Eisenberg, N., A. L. Duckworth, T. L. Spinrad, and C. Valiente. 2014. "Conscientiousness: Origins in Childhood?” Developmental Psychology 50 (5): 1331-49.

Frauke, P. 2016. "The Effect of Involuntary Maternal Job Loss on Children's Behaviour and Non-cognitive Skills." Labour Econ. 42: 43-63.

Friedman, H. S., M. L. Kern, and C. A. Reynolds. 2010. "Personality and Health, Subjective Well-Being, and Longevity." J. Personality 78 (1): 179-216.

Giuliano, P., and A. Spilimbergo. 2014. "Growing Up in a Recession." Rev. Econ. Studies 81 (2): 787-817.

Goldberg, L. R. 1993. "The Structure of Phenotypic Personality Traits." American Psychologist 48 (1): 26-34.

Goldberg, L. R., D. Sweeney, P. F. Merenda, and J. E. Hughes Jr. 1998. "Demographic Variables and Personality: The Effects of Gender, Age, Education, and Ethnic/Racial Status on Self-Descriptions of Personality Attributes." Personality and Individual Differences 24 (3): 393-403.

Greenstein, F. 1965. Children and Politics. New Haven, CN: Yale Univ. Press.

Guarino, C. M., M. D. Reckase, and J. M. Wooldridge. 2014. "Can Value-Added Measures of Teacher Performance Be Trusted?" Educ. Finance and Policy 10 (10): $117-56$.

Hainmueller, J. 2012. "Entropy Balancing for Causal Effects: A Multivariate Reweighting Method to Produce Balanced Samples in Observational Studies." Polit. Analysis 20 (1): 25-46.

Hampson, S. E., L. R. Goldberg, T. M. Vogt, and J. P. Dubanoski. 2007. "Mechanisms by which Childhood Personality Traits Influence Adult Health Status." Health Psychology 26 (1): 121-25.

Heckman, J. 2007. "The Economics, Technology, and Neuroscience of Human Capability Formation." Proc. Nat. Acad. Sci. USA 140 (33): 13250-55.

Heckman, J. J., J. Stixrud, and S. Urzua. 2006. "The Effects of Cognitive and Noncognitive Abilities on Labor Market Outcomes and Social Behavior." J. Labor Econ. 24 (3): 411-82.

Hess, R. D., and J. V. Torney. 1967. The Development of Political Attitudes in Children. Chicago: Aldine.

Hirano, K., G. W. Imbens, and G. Ridder. 2003. "Efficient Estimation of Average Treatment Effects Using the Estimated Propensity Score.” Econometrica 71 (4): 1161-89.

Hogan, J., and B. Holland. 2003. "Using Theory to Evaluate Personality and JobPerformance Relations: A Socio-analytic Perspective.” J. Appl. Psychology 88 (1): 100-112.

John, O. P., A. Caspi, R. W. Robins, T. E. Moffitt, and M. Stouthamer-Loeber. 1994. "The Little Five: Exploring the Nomological Network of the Five-Factor Model of Personality in Adolescent Boys." Child Development 65 (1): 160-78.

Kalil, A., and K. M. Ziol-Guest. 2008. "Parental Employment Circumstances and Children's Academic Progress.” Soc. Sci. Res. 37 (2): 500-515.

Kassenboehmer, S. C., and J. P. Haisken-DeNew. 2009. "You're Fired! The Causal Negative Effect of Entry Unemployment on Life Satisfaction.” Econ. J. 119 (536): 448-62. 
Kind, M., and J. P. Haisken-DeNew. 2012. "Unexpected Victims: How Parents' Unemployment Affects Their Children's Life Satisfaction.” Working paper, Melbourne Inst. Appl. Econ. and Soc. Res.

Krosnick, J. A., and D. F. Alwin. 1989. "Aging and Susceptibility to Attitude Change." J. Personality and Soc. Psychology 57 (3): 416-25.

Krueger, R. F., and W. Johnson. 2008. "Behavioral Genetics and Personality: A New Look at the Integration of Nature and Nurture." In Handbook of Personality: Theory and Research, edited by O. P. John, R. W. Robins, and L. A. Pervin, 287310. New York: Guilford.

Lucas, R. E., and M. B. Donnellan. 2011. "Personality Development across the Life Span: Longitudinal Analyses with a National Sample from Germany.” J. Personality and Soc. Psychology 101 (4): 847-61.

Marcus, J. 2013. "The Effect of Unemployment on the Mental Health of SpousesEvidence from Plant Closures in Germany.” J. Health Econ. 32 (3): 546-58.

Matud, M. P. 2004. "Gender Differences in Stress and Coping Styles." Personality and Individual Differences 37 (7): 1401-15.

McLoyd, V. C. 1989. "Socialization and Development in a Changing Economy: The Effects of Paternal Job and Income Loss on Children." American Psychologist 44 (2): 293-302.

Nunn, N., and L. Wantchekon. 2011. "The Slave Trade and the Origins of Mistrust in Africa." A.E.R. 101 (7): 3221-52.

Nyhus, E. K., and E. Pons. 2005. "The Effects of Personality on Earnings." J. Econ. Psychology 26 (3): 363-84.

O’Gorman, J. O., and E. Baxter. 2002. "Self-Control as a Personality Measure." Personality and Individual Differences 32 (3): 533-39.

Oster, E. 2017. "Unobservable Selection and Coefficient Stability: Theory and Evidence.” J. Bus. and Econ. Statis., forthcoming. doi:10.1080/07350015.2016 .1227711.

Piatek, R., and P. Pinger. 2015. "Maintaining (Locus of) Control? Data Combination for the Identification and Inference of Factor Structure Models." J. Appl. Econ. 31 (4): 734-55.

Pinger, P. 2015. "Understanding the Mechanisms behind Intergenerational Effects of Economic Distress.” Working paper, Univ. Mannheim.

Poropat, A. E. 2009. "A Meta-analysis of the Five-Factor Model of Personality and Academic Performance.” Psychological Bull. 135 (2): 322-38.

Powdthavee, N., and J. Vernoit. 2013. "Parental Unemployment and Children's Happiness: A Longitudinal Study of Young People's Well-Being in Unemployed Households.” Labour Econ. 24: 253-63.

Powdthavee, N., and A. Vignoles. 2008. "Mental Health of Parents and Life Satisfaction of Children: A Within-Family Analysis of Intergenerational Transmission of Well-Being." Soc. Indicators Res. 88 (3): 397-422.

Rege, M., K. Telle, and M. Votruba. 2011. "Parental Job Loss and Children's School Performance.” Rev. Econ. Studies 78 (4): 1462-89.

Roberts, B. W., and W. F. DelVecchio. 2000. "The Rank-Order Consistency of Personality Traits from Childhood to Old Age: A Quantitative Review of Longitudinal Studies." Psychological Bull. 126 (1): 3-25.

Roberts, B. W., N. R. Kuncel, R. Shiner, A. Caspi, and L. R. Goldberg. 2007. "The Power of Personality: The Comparative Validity of Personality Traits, Socioeconomic Status, and Cognitive Ability for Predicting Important Life Outcomes." Perspectives Psychological Sci. 2 (4): 313-45.

Roberts, B. W., and D. Mroczek. 2008. "Personality Trait Change in Adulthood." Current Directions Psychological Sci. 17 (1): 31-35.

Roberts, B. W., K. E. Walton, and W. Viechtbauer. 2006. "Patterns of Mean-Level Change in Personality Traits across the Life Course: A Meta-analysis of Longitudinal Studies." Psychological Bull. 132 (1): 1-25. 
Romano, J. P., and M. Wolf. 2005. "Stepwise Multiple Testing as Formalized Data Snooping." Econometrica 73 (4): 1237-82.

Ruhm, C. J. 2015. "Recessions, Healthy No More?” J. Health Econ. 42: 17-28.

Salgado, J. F. 1997. "The Five Factor Model of Personality and Job Performance in the European Community." J. Appl. Psychology 82 (1): 30-43.

Savelyev, P. A. 2014. "Socioemotional Skills, Education, and Longevity of HighAbility Individuals.” Working paper, Soc. Sci. Res. Network.

Sears, D. O. 1975. "Political Socialization." In Handbook of Political Science, edited by F. I. Greenstein and N. W. Polsby, 93-153. Reading, MA: Addison-Wesley.

1981. "Life Stage Effects on Attitude Change, Especially among the Elderly." In Aging: Social Change, edited by S. B. Kiesler, J. N. Morgan, and V. K. Oppenheimer, 183-204. New York: Academic Press.

. 1983. "The Persistence of Early Political Predispositions: The Role of Attitude Object and Life Stage.” In Review of Personality and Social Psychology, edited by P. R. Shaver and L. Wheeler, 79-116. Beverly Hills, CA: Sage.

Seery, M. D. 2011. "Resilience: A Silver Lining to Experiencing Adverse Life Events?" Current Directions in Psychological Sci. 20 (6): 390-94.

Seery, M. D., E. A. Holman, and R. C. Silver. 2010. "Whatever Does Not Kill Us: Cumulative Lifetime Adversity, Vulnerability, and Resilience." J. Personality and Soc. Psychology 99 (6): 1025-41.

SOEP (Socio-economic Panel). 2015. "Data for Years 1984-2013.” Version 30. SOEP, Berlin. doi:10.5684/soep.v30.

Stevens, A. H., and J. Schaller. 2011. "Short-Run Effects of Parental Job Loss on Children's Academic Achievement.” Econ. Educ. Rev. 30 (2): 289-99.

Stratta, P., C. Capanna, I. Riccardi, et al. 2012. "Suicidal Intention and Negative Spiritual Coping One Year after the Earthquake of L'Aquila (Italy)." J. Affective Disorders 136 (3): 1227-31.

Todd, P. E., and K. I. Wolpin. 2003. "On the Specification and Estimation of the Production Function for Cognitive Achievement.” Econ. J. 113 (485): F3-F33.

Wagner, G., J. Frick, and J. Schupp. 2007. "The German Socio-Economic Panel Study (SOEP): Scope, Evolution and Enhancements.” Schmollers Jahrbuch 127 (1): $139-69$. 